\title{
PROTEÍNA TOTAL, PROTEINOGRAMA ELETROFORÉTICO E GAMAGLUTAMILTRANSFERASE DE BEZERRAS COM 30 HORAS DE VIDA NO MUNICÍPIO DE CAMPO LARGO, PARANÁ
}

\author{
Total Protein, Electrophoretic Proteinogramme and Gama Glutamyl \\ Transferase of Calves with 30 Hours of Life in the Municipality \\ of Campo Largo, Parana State
}

João Ari Gualberto Hill

Médico Veterinário, M.Sc., Prof. da UTP, Curitiba - PR. e-mail: joao.hill@utp.br

Douglas Wosch Costa

Médico Veterinário, Curitiba - PR.e-mail: joao.hill@utp.br, joao.hill@utp.br

Marly Elizabete Ferreira de Castro

Laboratorista da FMVZ USP, São Paulo - SP. e-mail: joao.hill@utp.br

Welington Hartmann

Médico Veterinário, Dr., Prof. da UTP, Curitiba - PR. e-mail: welington.hartmann@utp.br

Fernando José Benesi

Médico Veterinário, Pós-Doutor, Prof. da FMVZ USP, São Paulo - SP. e-mail: febencli@usp.br

\section{Resumo}

O presente estudo foi realizado no município de Campo Largo - PR, região metropolitana de Curitiba, em que as bezerras nascidas em duas propriedades leiteiras tiveram seu sangue colhido às 30 horas de vida e analisado para proteína sérica total (PT), albumina (ALB), globulina (GLOB), alfaglobulina (ALFA), betaglobulina (BETA), gamaglobulina (GAMA) e a enzima gamaglutamiltransferase (GGT). As correlações entre os diversos parâmetros foram verificadas com o objetivo de demonstrar que testes simples, como a proteína sérica total, são úteis no diagnóstico de falha na transferência de imunidade passiva colostral. A enzima gamaglutamiltransferase (GGT) também foi testada, observando-se que os seus níveis séricos muito baixos indicam falha no processo de transferência, apesar da grande variação no seu valor absoluto nos diferentes indivíduos, sugerindo mais estudos em relação a ela. As médias obtidas em gramas por decilitro de soro foram, para PT de 6,492, ALB 2,386, GLOB 4,107, ALFA 1,612, BETA 1,089, GAMAGLOBULINA 1,686 e GGT 1174,29.

Palavras-chave: Colostro; Neonatologia; Leite; Imunoglobulinas; Imunidade passiva. 


\begin{abstract}
This study was accomplished in the municipality of Campo Largo - Paraná, metropolitan region of Curitiba, where the calves, born in two milk establishments, had their blood gathered at their thirty hours of life, and analised for total protein (PT), albumin (ALB), alpha globulin (ALFA), beta globulin (BETA), gamma globulin (GAMA), and the activity of gamma glutamyl transferase (GGT). The correlations among the different parameters were tested with the objective of demonstrating that simple tests like the total protein are useful in the diagnostic of failure in the transference of colostral passive immunity. The activity of gama glutamyl transferase (GGT) was also tested by observing that the very low levels of this enzyme indicate failure in the process of transference, despite the great variation in the absolute values of this enzyme in the different individuals suggesting more studies in relation to it. The averages obtained in grams per deciliter $(\mathrm{g} / \mathrm{dL})$ of serum were for PT 6.492, ALB 2.386, GLOB 4.107, ALFA 1.612, BETA 1.089, GAMA 1.686 and GGT 1174.29.
\end{abstract}

Keywords: Colostrums; Neonatology; Milk; Immunoglobulin; Passive immunity.

\title{
INTRODUÇÃO
}

Nos bovinos, assim como em outros ruminantes, a transferência da imunidade materna se dá pela ingestão do colostro, isto é, após o nascimento. Os anticorpos atravessam a barreira epitelial do intestino delgado, garantindo ao recém-nascido a proteção adequada para as primeiras semanas de vida (BRAMBELL, 1958).

Tiselius (1937) foi o primeiro pesquisador a realizar o fracionamento das proteínas séricas. Essas são fracionadas em albumina, alfaglobulina, betaglobulina e gamaglobulina. A gamaglobulina, produzida pelos linfócitos e células plasmáticas, conteria anticorpos, denominados genericamente de imunoglobulinas (SWENSON, 1988). A eletroforese das proteínas séricas é um método valioso para a determinação quantitativa das proteínas séricas, sendo de particular importância para avaliação dos níveis de gamaglobulinas presentes no soro (OLIVEIRA; VOGEL, 1984).

Baroni, Molfi e Baron (1982), em 100 bezerros da raça holandesa entre quatro e oito meses de vida, observaram valor médio de 7,07 $\pm 0,06 \mathrm{~g} / \mathrm{dl}$ de proteína total. Pinheiro, Ribeiro e Nascimento (1983) verificaram taxa média de proteína total de $8,71 \pm 1,08 \mathrm{~g} / \mathrm{dl}$ em bezerros com idade entre dois e dez meses. Naylor e Kronfeld (1977), ao avaliarem o aumento nos níveis de proteína plasmática total após a ingestão de colostro, observaram aumento nos valores de 2,03 $\pm 0,6 \mathrm{~g} / \mathrm{dl}$. Braun et al. (1982) demonstraram que a elevação dos níveis de proteína plasmática total ocorreu durante os dois primeiros dias de vida dos bezerros após a ingestão do colostro.

Susin et al. (1987), após realizarem 13 colheitas seriadas em bezerros da raça Holandesa, durante os primeiros 60 dias de vida, constataram que a concentração máxima de proteína total foi observada na $24^{a}$ hora pós-nascimento, com valor médio de 8,1 $\pm 0,76 \mathrm{~g} / \mathrm{dl}$. Perino e Wittum (1995) realizaram dosagem da proteína total sérica em 143 bezerros mantidos com as mães e encontraram valores

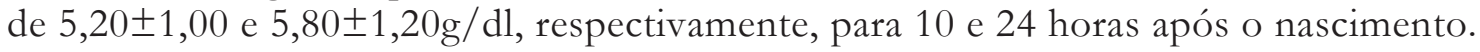

Braun et al. (1982) observaram que a elevação dos níveis das frações beta e gamaglobulinas no soro sangüíneo de bezerros ocorreu após a ingestão de colostro. Fagliari et al. (1996) estudaram 140 bezerros do primeiro ao sexto dia de vida e observaram baixa concentração sérica de gamaglobulinas nas primeiras seis horas de vida $(0,56 \pm 0,27 \mathrm{~g} / \mathrm{dl})$, alcançando nível máximo 24 a 30 horas após o nascimento $(2,08 \pm 0,40 \mathrm{~g} / \mathrm{dl})$.

Benesi (1996) cita que os percentuais médios de mortalidade em bezerros são bastante altos, em especial pela diarréia. Países como Alemanha, Dinamarca, Estados Unidos e Brasil registram 8\%, 8\%, $10 \%$ e $25 \%$, respectivamente, de mortalidade determinada pela diarréia em bezerros e essa se apresenta como resultante da interação entre o bezerro, seu ambiente, a nutrição recebida e os agentes infecciosos existentes na propriedade. 
Pela importância dos bezerros na propriedade leiteira, por representarem as futuras gerações e o trabalho de melhoramento genético que o proprietário se esforçou em conseguir, trabalhos adicionais devem ser conduzidos para evitar a mortalidade, principalmente nos animais recém-nascidos. O diagnóstico precoce de falha na transferência da imunidade passiva nas criações de bezerros é fundamental para que alterações no manejo possam ser implementadas. Por isso, este trabalho teve como objetivo verificar os níveis de proteína sérica total e de suas frações eletroforéticas em bezerros que receberam colostro de duas fazendas da região metropolitana de Curitiba - PR, assim como verificar a correlação entre a proteína sérica total e sua correlação entre as frações albumina, globulina, alfa, beta e gamaglobulinas. A proteína sérica total pode ser testada facilmente por um grande número de laboratórios a baixo custo. Para isso, a hipótese de que a variação dos níveis de proteína sérica total nos bezerros com 30 horas de vida representa a alteração da fração gamaglobulina que contém as imunoglobulinas, fundamentais para o bezerro resistir as novas infecções, deve ser testada.

\section{MATERIAIS E MÉTODOS}

O estudo foi desenvolvido em 2 propriedades, na região metropolitana de Curitiba, no município de Campo Largo, no Estado do Paraná.

As amostras foram colhidas de $100 \%$ das bezerras vivas até o momento da colheita $(24-36$ horas após o nascimento), durante o período de julho e agosto de 2005, perfazendo um total de 16 amostras.

\section{COLHEITA DE SANGUE E PREPARO DAS AMOSTRAS}

A colheita de sangue para a obtenção de soro foi realizada por punção da veia jugular após assepsia local, utilizando-se agulhas $25 \times 8 \mathrm{~mm}$, acopladas a tubos vacutainer com gel separador siliconizados. O sangue, colhido em 2 frascos com capacidade de $6 \mathrm{ml}$ das bezerras com 30 horas de vida ( \pm 6 horas), foi mantido em temperatura ambiente por aproximadamente 6 horas. Após retração do coágulo, o soro das amostras foi separado e acondicionado em geladeira, de onde semanalmente eram remetidas para o laboratório. Essas amostras eram centrifugadas a $3000 \mathrm{rpm}$, durante 10 minutos, para eliminação de possíveis células e resíduos. O soro foi transferido em alíquotas para frascos de plástico apropriados, com auxílio de pipeta automática e mantido em congelador a $-20^{\circ} \mathrm{C}$ até o momento do seu processamento. Para a realização das avaliações laboratoriais, o descongelamento das amostras foi feito deixando-as à temperatura ambiente.

\section{DETERMINAÇÕES BIOQUÍMICAS}

\section{Fracionamento das proteínas séricas}

Para determinação da albumina, globulina, alfaglobulina, betaglobulina e gamaglobulina séricas, foi utilizada a eletroforese das proteínas existentes no soro. Para o fracionamento, foi realizada a migração eletroforética em fitas de acetato de celulose, de 5,7 x $14 \mathrm{~cm}$ por meio de técnicas modificadas de Friedman, (1961) e Kremers et al. (1967) e Borges, (1997).

\section{Proteína sérica total}

Para a determinação das proteínas séricas totais foi utilizado o método do Biureto, Gornall et al. (1949), modificado por Strufaldi (1987) e Feitosa (1998), que utiliza um analisador bioquímico RA-100 ${ }^{1}$ em comprimento de onda de $550 \mathrm{~nm}$.

\footnotetext{
$\overline{{ }^{1} \text { Bayer - Technicom modelo RA } 100^{\mathrm{tm}} \text { system. }}$
} 


\section{Gama glutamil transferase sérica}

A atividade da gama-glutamiltransferase sérica (GGT) foi determinada pelo método cinético colorimétrico, baseado na ação catalítica da GGT sobre a L-gama-glutamil-transferase-3-carboxi-4nitranilida e glicilglicina, originando a L-gama-glutamilglicina e 5 amino-2-nitrobenzoato. Para isso, foi utilizado o "kit" comercial, ${ }^{2}$ segundo citação de Feitosa (1998).

\section{ANÁLISE DOS RESULTADOS}

Para determinação dos valores de referência nos bezerros, foi realizada a estatística descritiva pela determinação dos valores de tendência central (média e mediana) e dos valores de dispersão (desviopadrão, coeficiente de variação e valores mínimo e máximo) para cada variável e foram também determinadas as correlações entre as variáveis estudadas.

\section{RESULTADOS E DISCUSSÃO}

Os resultados obtidos para as concentrações séricas de proteína total, albumina, globulina, alfaglobulina, betaglobulina e gamaglobulina associados aos elementos de estatística descritiva (média, desvio-padrão, coeficiente de variação e valores mínimo e máximo), bem como o coeficiente de correlação entre essas variáveis, estão apresentados nas Tabelas 1 e 2.

TABELA 1 - Valores médios da concentração de proteína total (P'T), albumina (ALB), globulina (GLOB), alfaglobulina (ALFA), betaglobulina (BETA), gamaglobulina (GAMA)

e gamaglutamiltransferase (GGT) do soro sangüíneo de bezerros neonatos, 30 horas

( \pm 6 horas) após o nascimento, com valores de estatística descritiva - média, desvio-padrão,

coeficiente de variação, valor mínimo e máximo, em Campo Largo - PR, 2005

Table 1 - Average values of the concentration of total protein (SPT), albumin (ALB), Globulin (GLOB), alfaglobulin (ALFA), betaglobulin (BETA), gammaglobulin (GAMA) and gammaglutamyltransferase (GGT) from de blood serum neobovine, 30 hours ( \pm 6 hours) after birth, with values of descriptive statistic: average, standard deviation, coefficient of variation, minimum and maximum values, in Campo Largo - PR, 2005

\begin{tabular}{lrrrrr}
\hline & $\begin{array}{r}\text { Média } \\
(\mathrm{g} / \mathrm{dL})\end{array}$ & $\begin{array}{r}\text { Desvio } \\
\text { Padrio }\end{array}$ & $\begin{array}{r}\text { Coeficiente de } \\
\text { Variacio }\end{array}$ & $\begin{array}{r}\text { Valor } \\
\text { mínimo }\end{array}$ & $\begin{array}{r}\text { Valor } \\
\text { míximo }\end{array}$ \\
\hline PT (total protein) & 6,492 & 1,109 & 17,08 & 4,805 & 8,760 \\
AL.B (albumin) & 2,386 & 0,185 & 7,77 & 2,035 & 2,637 \\
GLOB (globulin) & 4,107 & 0,161 & 28,29 & 2,168 & 6,436 \\
AL.FA (alphaglobulin) & 1,612 & 0,112 & 6,96 & 1,456 & 1,781 \\
BETA (betaglobulin) & 1,089 & 0,323 & 29,63 & 0,583 & 1,818 \\
GAMA (gammaglobuline) & 1,686 & 0,744 & 44,10 & 0,398 & 3,152 \\
\hline GGT (gamma glutamyl transferase) & 1174,290 & 851,931 & 72,55 & 9,240 & 2978,500 \\
\hline
\end{tabular}

\footnotetext{
${ }^{2}$ Boehringer Mannheim - ã-GT, MPR. 1
} 
Os valores encontrados para proteína sérica total são próximos aos de Feitosa (1998), cuja média foi de $6,55 \mathrm{~g} / \mathrm{dl}$, mas superiores àqueles encontrados por Kaneko e Mills (1970) e Naylor et al. (1977), respectivamente, 5,2 e 4,4 g/dl de soro. Birgel et al. (1964), testando a proteína sérica de fêmeas entre 2 e 5 meses, encontraram valores médios superiores, 7,65 \pm 0,21 $\mathrm{mg} / \mathrm{dl}$ de soro.

Os valores referentes à gamaglobulina foram semelhantes àqueles encontrados por Fagliari et al. (1988), quando testaram o soro de bezerros da raça guzerá aos 2 dias $(1,55 \pm 0,52)$. Tennant et al. (1969) observaram valores de 1,3 g/dl e Feitosa (1998), trabalhando com bezerros da raça holandesa, 24 horas após a ingestão do colostro, encontrou valores médios de gamaglobulina de 2,14 g/ dl.

A Tabela 2 mostra a correlação entre os resultados determinados para os valores aferidos no soro.

TABELA 2 - Correlação entre os resultados determinados para a concentração de proteína total (PT), albumina (ALB), globulina (GLOB), alfaglobulina (ALFA), betaglobulina (BETA), gamaglobulina (GAMA) e gamaglutamiltransferase (GGT) do soro sanguíneo de bezerros neonatos, 30 horas ( \pm 6 horas) após o nascimento, em Campo Largo - PR, 2005

Table 2 - Correlation between the results of the serum total protein (PT), albumin (ALB), globulin (GLOB), alphaglobulin (ALFA), betgaglobulin (BETA), gammaglobulin (GAMA) and gama glutamyl transferase (GGT) of the calves, 30 hours ( \pm 6 hours) of age in Campo Largo - PR, 2005

\begin{tabular}{lrrrrrr}
\hline & ALB & GLOB & ALFA & BETA & GAMA & GGT \\
\hline PT & $-0,21$ & 0,9877 & 0,068 & 0,882 & 0,973 & 0,343 \\
ALB & 1 & $-0,3577$ & 0,725 & $-0,402$ & $-0,334$ & $-0,758$ \\
GLOB & & 1 & $-0,05$ & 0,907 & 0,982 & 0,448 \\
ALFA & & & 1 & $-0,144$ & $-0,087$ & $-0,437$ \\
BETA & & & & 1 & 0,841 & 0,415 \\
GAMA & & & & & 1 & 0,223 \\
GGT & & & & & & 1 \\
\hline
\end{tabular}

É importante ressaltar a alta correlação positiva entre a proteína sérica total e a gamaglobulina $(0,973)$, assim como a relação entre proteína total e globulinas $(0,982)$.

\section{CONCLUSÕES}

O valor médio da gamaglutamiltransferase foi de 1174,29 UI, com grande variação entre as amostras, o que sugere a necessidade da realização de maiores estudos sobre essa enzima nos bovinos recém-nascidos.

As taxas de proteína total e da fração da gamaglobulina do soro apresentaram alta correlação entre si. Portanto, a aferição da proteína total sérica dos bezerros recém-nascidos com 30 horas após o nascimento serve como parâmetro médico para o diagnóstico de falha na transferência da imunidade passiva colostral. 


\section{REFERÊNCIAS}

BARONI, D. S. F.; MOLFI, A.; BARONI, J. M. Teores normais de proteína plasmática total em bovinos jovens da raça Holandesa Preta e Branca. Arq. Biol. Tecnol., Curitiba, v. 25, p. 233-235, 1982.

BENESI, F. J. Diarréia infecciosa neonatal dos bezerros. In: SIMPÓSIO PFIZER SOBRE DOENÇAS INFECCIOSAS E VACINAS PARA BOVINOS, 1., 1996. Guarulhos. Anais... Guarulhos: Laboratório Pfizer, 1996. p. 15-24.

BIRGEL, E. H. et al. Considerações sobre o teor de proteína total, albuminas, globulinas e relação albumina/globulina no plasma de 3 lotes de bovinos da raça hereford. Arquivos do Instituto Biológico, São Paulo, v. 31, n. 4, p. 103-110, 1964.

BORGES, A. S. Avaliação da eficácia da administração de plasma, por via intravenosa, como tratamento da falência de transferência de imunidade passiva em bezerros da raça Holandesa. 84 f. Dissertação (Mestrado em Clínica Veterinária)- Faculdade de Medicina Veterinária e Zootecnia de São Paulo, São Paulo, 1997.

BRAMBELL, F. W. R. The passive immunity of the young mamal. Biological Revews, Cambridge, v. 33, p. $488-531,1958$.

BRAUN , J. P. et al. Early variations fo blood plasma gama glutamyl transferase in newborn calves: a test of colostrum intake. Journal of Dairy Science, Savoy, v. 65, n. 11, p. 2178 - 2181, 1982.

FAGLIARI, J. J. et al. Relação entre o nível sérico de gamaglobulinas e as atividades de gamaglutamiltransferase, fosfatase alcalina e aspartatoaminotransferase de bezerros recém-nascidos. Arquivo Brasileiro de Medicina Veterinária e Zootecnia, Belo Horizonte, v. 48, n. 2, p. 105-112, 1996.

FAGLIARI, J. J. et al. Valores padrões das proteínas séricas de bovinos da raça Guzerá II. Proteinograma sérico de bezerros recém-nascidos. Ars Veterinária, Campo Grande, v. 4, n. 2, p. 225-232, 1988.

FEITOSA, F. L. F. Dinâmica do proteinograma e da atividade da gamaglutamiltransferase no soro sangüíneo de bezerros desde o nascimento até um ano de idade e de vacas, antes e após o parto, da raça holandesa. 219 f. Tese (Doutorado em Clínica Veterinária) - Faculdade de Medicina Veterinária e Zootecnia de São Paulo, São Paulo, 1998.

KANEKO, J. J.; MILLS, R. Hematological and blood chemical observation in neonatal normal and porphyric calves in early life. Cornell Veterinary, Ithaca, v. 60, n. 1, p. 52-60, 1970.

NAYLOR, J. M.; KRONFELD, D. S. Refractometry as a measure of the immunoglobulin status of the newborn dairy calf: comparison with the zinc sulfate turbidity test and single radial immunodifusion. American Journal of Veterinary Research, Schaumburg, v. 38, n. 9, p. 1331-1339, 1977.

NAYLOR, J. M. et al. Plasma total protein measurement for prediction of disease and mortality in calves. Journal of the American Veterinary Medical Association, Schaumburg, v. 171, n. 7, p. 635-638, 1977.

OLIVEIRA, A. R.; VOGEL, J. Proteínograma eletroforético de bovinos normais da raça Canchim. Revista Brasileira de Medicina Veterinária, Campo Grande, v. 6, n. 5, p. 165-166, 1984.

PERINO, L. J.; WITTUM, T. E. Effects of various risk factors on plasma protein and serum inmunoglobulin concentrations of calves at postpartum hours 10 and 24. American Journal of Veterinary Research, Schaumburg, v. 56, n. 9, p. 1144-1148, 1995. 
PINHEIRO, J. G.; RIBEIRO, A. G. P.; NASCIMENTO, M. D. Proteínas totais plasmáticas e fibrinogênio em bezerros de pré ano no município de Cantagalo. Comunicado Técnico, Rio de Janeiro, v. 127, n. 1/2, abr. 1983.

SUSIN, I. et al. Imunoglobulina e proteína total séricas em bezerros holandeses e mestiços. Revista da Sociedade Brasileira de Zootecnia, Viçosa, v. 16, n. 2, p. 588-592, 1987.

SWENSON, M. J. D. Fisiologia dos animais domésticos. Rio de Janeiro: Guanabara Koogan, 1988.

TENNANT, B. et al. Neonatal alterations in serum gamma globulin levels of Jersey and Holstein-Frisiean calves. American Journal of Veterinary Research, Schaumburg, v. 30, n. 3, p. 345-354, 1969.

TISELIUS, A. Electrophoresis of serum globulin. Biochemical Journal, La Jolla, v. 31, p. 313-337, 1937.

Recebido em: 02/12/2006

Received in: $12 / 02 / 2006$

Aprovado em: 30/03/2007

Approved in: 03/30/2007 